\title{
Article
}

\section{Specifications grading: What it is and lessons learned}

\author{
Leslie, Paula and Lundblom, Erin
}

Available at http://clok.uclan.ac.uk/33352/

Leslie, Paula ORCID: 0000-0002-0379-9044 and Lundblom, Erin (2020)

Specifications grading: What it is and lessons learned. Seminars in Speech and Language, 41 (4). pp. 298-309. ISSN 0734-0478

It is advisable to refer to the publisher's version if you intend to cite from the work. http://dx.doi.org/10.1055/s-0040-1713781

For more information about UCLan's research in this area go to

http://www.uclan.ac.uk/researchgroups/ and search for < name of research Group>.

For information about Research generally at UCLan please go to http://www.uclan.ac.uk/research/

All outputs in CLoK are protected by Intellectual Property Rights law, including Copyright law. Copyright, IPR and Moral Rights for the works on this site are retained by the individual authors and/or other copyright owners. Terms and conditions for use of this material are defined in the policies page.

\section{CLoK}

Central Lancashire online Knowledge www.clok.uclan.ac.uk

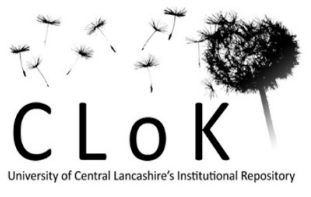




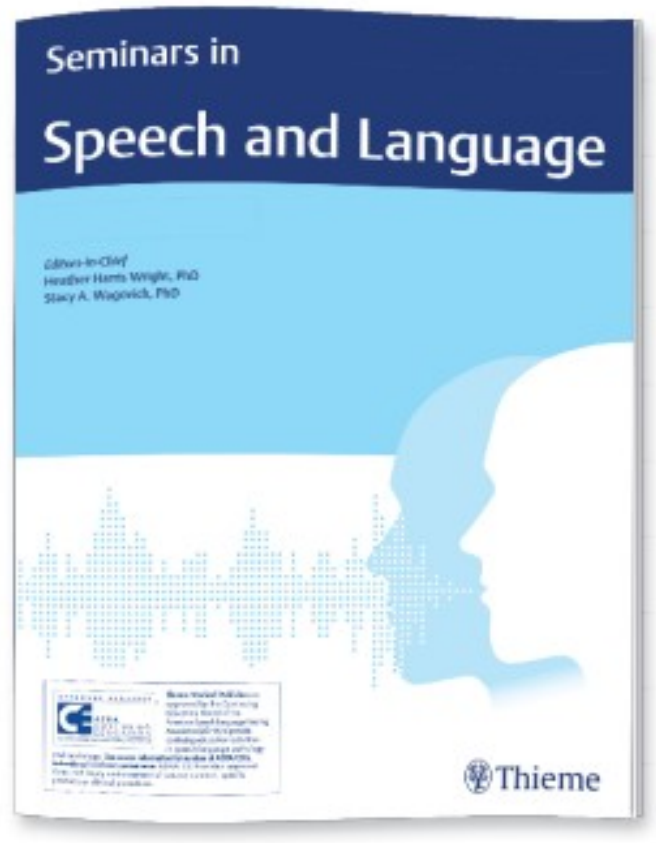

\section{Specifications grading: What it is and lessons learned}

\begin{tabular}{|c|c|}
\hline Journal: & Seminars in Speech and Language \\
\hline Manuscript ID & SSL-20-0016-IA.R2 \\
\hline Manuscript Type: & Invited Review (Solicited) \\
\hline $\begin{array}{r}\text { Date Submitted by the } \\
\text { Author: }\end{array}$ & $\mathrm{n} / \mathrm{a}$ \\
\hline Complete List of Authors: & $\begin{array}{l}\text { Leslie, Paula ; University of Central Lancashire, School of Sport \& Health } \\
\text { Sciences } \\
\text { Lundblom, Erin; University of Pittsburgh, Communication Science \& } \\
\text { Disorders }\end{array}$ \\
\hline Keywords: & Grade, Education, Standards, Competency, Outcomes \\
\hline Abstract: & $\begin{array}{l}\text { Traditional point-based grading is failing students entering a } \\
\text { competency-based workforce: employers require concrete skills and } \\
\text { knowledge not "high" grades. In the specifications approach, learning } \\
\text { outcomes are explicitly linked to the grading system. The basic } \\
\text { components of the approach include: clear alignment of learning } \\
\text { outcomes to certification standards, bundled sequences of assessments } \\
\text { tied to basic and advanced competency/learning outcomes, pass/fail } \\
\text { grading with no partial credit, opportunities to revise unacceptable work, } \\
\text { and detailed expectations of performance on assessments. This article } \\
\text { describes the specifications approach and provides examples highlighting } \\
\text { how to (a) align course learning objectives with a grading system, (b) } \\
\text { implement a pass/fail approach even for complex assessment, (c) define } \\
\text { specifications, (d) create and sequence bundles of assessments, and (e) }\end{array}$ \\
\hline
\end{tabular}


1

2

3

4

5

6

7

8

9

10

11

12

13

14

15

16

17

18

19

20

21

22

23

24

25

26

27

28

29

30

31

32

33

34

35

36

37

38

39

40

41

42

43

44

45

46

47

48

49

50

51

52

53

54

55

56

57

58

59

60 provide instructor support through feedback and tokens.

SCHOLARONE ${ }^{\text {M }}$

Manuscripts 
Disclosures

Paula Leslie, PhD, FRCSLT, CCC-SLP (Contact)

Senior Lecturer Speech \& Language Therapy

School of Sport \& Health Sciences

University of Central Lancashire

Preston

PR1 2HE

United Kingdom

PLeslie1@uclan.ac.uk

Erin Lundblom PhD, CCC-SLP

Associate Professor

Department of Communication Science and Disorders

School of Health and Rehabilitation Sciences

University of Pittsburgh

3600 Forbes at Atwood

6035 Forbes Tower

Pittsburgh, PA 15260

lundblom@pitt.edu 


\section{Key Words}

Grade, education, standards, competency, outcomes

\section{Learner Outcomes}

After reading this article, the learner will be able to

1. Describe the rationale for specifications grading in clinical coursework

2. Identify the basic components of specifications grading

3. Explain how to apply components of the specifications grading approach to a course

\section{Abstract}

Traditional point-based grading is failing students entering a competency-based workforce: Employers require concrete skills and knowledge, not "high" grades. In the specifications approach, learning outcomes are explicitly linked to the grading system. The basic components of the approach include: clear alignment of learning outcomes to certification standards, bundled sequences of assessments tied to basic and advanced competency/learning outcomes, pass/fail grading with no partial credit, opportunities to revise unacceptable work, and detailed expectations of performance on assessments. This article describes the specifications approach and provides examples highlighting how to (a) align course learning objectives with a grading system, (b) implement a pass/fail approach even for complex assessment, (c) define specifications, (d) create and sequence bundles of assessments, and (e) provide instructor support through feedback and tokens. 


\section{CEU Questions}

1) The purpose of grading in academic courses is to:
a) Help determine salary information for employers
b) Identify student learning and provide feedback*
c) Support students' obtaining scholarships
d) Provide attendance information to parents
e) Recruit more students to the major

2) Advantages in traditional grading include:
a) Students and instructors are familiar with it*
b) Grading is highly reliable across students and cohorts
c) Grading of assignments is highly efficient
d) Grades always map to specific skill acquisition
e) Partial credit for effort makes grading easier

3) Professional degrees with external standards require which of the following from grading?
a) Only description of knowledge outcomes
b) Only knowledge of skill outcomes
c) Demonstration of knowledge and skill outcomes*
d) Mapping to Praxis standards
e) Consultation with educational specialists for course design 
5) The purpose of tokens in Specifications Grading is:
a) As a form of behavior management
b) To reinforce students for learning content
c) To compensate students for classroom efforts
d) To teach students to associate tokens with learning
e) To pass control of the learning process over to the student * 


\section{Introduction}

In considering the purpose of grading academic work, commonsense suggests that there needs to be some external judgment of what is learned rather than the student deciding that they have mastered knowledge satisfactorily. Centuries of developing expertise through an apprenticeship model have given way to pen and paper tests of knowledge, practical assessments, and oral defenses. Lurie ${ }^{1}$ provided a detailed history of competency-based assessment in medicine which mirrors that of our own field. Not until the middle of the last century did regulatory bodies gain traction as judges of academic standards and professional competence, rather than educational institutions.

Educational establishments use grades as a way of assessing an individual's knowledge but also to demonstrate that the institutions are meeting benchmarks of learning. Grading provides a mechanism to assess knowledge, identify strengths and weaknesses, and give feedback, so that new learning occurs on a solid foundation of factual knowledge. In professional education, we need to address more than factual knowledge. Clinical students need to develop behaviors, practical skills, and emotional intelligence, all of which contribute to competency on the job. Clinical fields, including audiology and speech-language pathology, focus on knowledge and skill-based outcomes. This leads to questions as to whether our academic grading system aligns with the measurement of concrete knowledge and skills required by employers, state licensing boards, and accreditation agencies.

\section{Traditional grading}

Most educational institutions use a letter grade scale with values ranging from $\mathrm{A}$ to $\mathrm{F}$. Instructors derive letter grades using point-based grading systems, with students accumulating points across a course. The instructor may calculate a percentage score by dividing earned 
作

For example, 90 to $100 \%$ is an A, 80 to $89 \%$ a B, 70 to $79 \%$ a C, and so on. The instructor assigns the letter grade associated with the student's earned percentage and may more finely distinguish grades with pluses and minuses. For example, a student may earn a $\mathrm{C}$ - for a $72 \%$, a B for an $86 \%$ or an $\mathrm{A}+$ for a $99 \%$. In this system it can be a challenge for an instructor or student to know what was mastered to receive one of these grades. Does a $99 \%$ represent exceptional mastery and a $72 \%$ some mastery? If a student earned a $99 \%$ in a course, did the student achieve all knowledge or skill outcomes at a high level, or were some achieved at a satisfactory level? For lower grades, like $72 \%$ or $88 \%$, it is difficult to tell whether the student attained at least a minimal baseline of the requisite knowledge and skills or not.

The traditional point-based grading system leads to difficulty identifying the knowledge or skill in which a student demonstrated competency associated with the points earned and corresponding grade. Grades no longer map to enhanced skill or knowledge, but reflect the degree to which a student meets an instructor's expectations. ${ }^{2}$ As a byproduct of the traditional point-based grading system, students tend to argue with instructors about each point lost (termed grade grubbing), in order to receive the highest possible grade, leading to grade inflation and ultimately eroding the meaning of grades. Instructors spend countless hours subjectively grading (e.g., papers, assignments, examinations, lesson plans, clinical documentation, etc.), striving to be fair, which contributes considerably to the teaching burden. In light of these issues, we might ask if grades are accomplishing what we need: to document that a student has attained the knowledge or skill required for professional entry.

Commented [PRW1]: I know this was edited out of the original document but I think it's important to name this in a way consistent with the specs literature. This is what it's called by those who write about and use specs grading so I think it's nice to provide this term to those just learning about the approach from this manuscript. It's a MAJOR benefit to this approach (eliminates grade grubbing)

Commented [WSA2R2]: Ok, I didn't realize this was a term. Makes sense to include. 


\section{Challenges with traditional grading approaches within clinical disciplines}

Grades are determined at the course level by an instructor aiming for reliability and efficiency. Instructors determine how many points to allocate to each student for any submitted test or assignment. But, even with well-developed rubrics, point allocation is subjective, and the instructor often must make a personal judgement. Instructors naturally strive for consistency, so they often review papers after initial grading to gauge similarities in point allocation across papers and adjust as needed. Consider this task across many students and multiple items. Given the ever-increasing workload in higher education, this iterative grading process can be timeprohibitive, which may then influence the types of course assessments instructors select. For example, instructors may rely on examinations with a test bank of questions and electronic scoring, rather than a more authentic or applied measure of learning, such as a written case application scenario in which students submit an assessment protocol and complete an oral examination, explaining diagnostic results and offering treatment recommendations. The latter approach, while superior in assessing practical learning outcomes, is clearly more time-intensive than composing an assessment using a test bank.

Another challenge associated with traditional grading is the use of partial points. This is a largely subjective task, plagued with threats to reliability both within and between instructors. Because of this inherent subjectivity, it is necessary to document knowledge and skills outcomes beyond the course level, through assessment at the programmatic level, such as a capstone experience or a comprehensive exam. Assessments at the institution level culminate in sitting for the standardized Praxis test to earn national certification. 
In addition, traditional point-based grading with partial credit encourages students to focus on points received, rather than focusing on demonstrated knowledge and the need for continued learning to demonstrate competence. Points become an extrinsic motivator, and the student's exclusive focus on the number of points earned causes considerable distress from early on in schooling. ${ }^{3}$ Ultimately, over-focusing on grades and points results in the student's deemphasis of mastery of skills and of development of the lifelong learning habits of a competent clinical professional.

Given the inherent problems with the traditional system of grading, it is reasonable to question whether our current point-based grading approach has lost sight of the nature and purpose of learning. In clinical professions, we need to enable the development of skills and competencies and to measure these in such a way that we ensure the student's readiness to enter the profession. Traditional assessment is rarely adequate if limited to multiple-choice exams or lengthy written essays. Rather, clinical fields require a defined set of knowledge and skills to enter the occupation. Many of these skills and competencies are essentially present or absent and further defining them by a points system is, therefore, problematic.

\section{An alternative grading approach}

In the traditional point-based grading approach, the problem is not the resulting letter grade but the reliance on points. An important aim, then, should be to improve current practice for instructors and students. In the assignment of letter grades, instead of linking grades to point values, they might be linked instead to demonstrations of specific knowledge and skills. That is, assessment should ideally:

- reflect learning outcomes through explicit linkage of knowledge and skills to grades

- motivate students to learn and excel at learning 
- develop students' responsibility for lifelong learning

- $\quad$ provide clear expectations

- use authentic assessment measures

- offer efficient and meaningful instructor feedback

- $\quad$ provide opportunity for the student to learn from instructor feedback

This shift in assessment focus may seem far too complex. Change is certainly difficult. (For example, the use of car seat belts in the United States took decades of public awareness and legislation to reach consistent use. ${ }^{4}$ ) Despite the complexity of shifting our grading system, the results of doing so could be profound, in terms of the learning outcomes of our students.

A learning-centered model posits that students learn more effectively when they are actively involved in the process, receive frequent feedback, and view their instructor as a facilitator of learning. ${ }^{6}$ Learning in the classroom requires trial-and-error, taking chances, struggling, and failing, all of which mirrors the authentic workplace. The two environments differ in that students are often discouraged from taking risks and are penalized when they try but fail in academic settings. This negative experience develops into a fear of trying and exploring and contributes to a focus on what do I need to know to pass? Alternative grading systems may provide a bridge for instructors and students to move past the perceived challenges of change and adopt learning-centered approaches.

In general, changes are adopted more rapidly when they are perceived as having greater advantages, are less complex, and are consistent with existing needs. ${ }^{7}$ Specifications grading ("specs grading") is a practical approach that encompasses learning-centered components, competency-based education, and contract grading. ${ }^{2}$ The basic tenets of the approach emphasize student learning outcomes and acknowledge the overlap between the concepts of grading and 
assessment. Specifications grading empowers students to consider the required learning outcomes for a course, fosters intrinsic motivation through clear expectations, and creates active learners who are receptive to meaningful feedback. ${ }^{2}$ The core principles of specifications grading are that:

- course assessments are aligned with course learning objectives

- expectations ("specifications") are clear

- students decide what grade they aim for (self-imposing learning demands consistent with the grade)

- feedback relates expectations to performance

- defined (and limited) options are provided for revisions

- assessments are completed at a clearly defined level of performance (e.g., corresponding to a grade of $\mathrm{B}$ or $\mathrm{C}$ ) to demonstrate competency

- advanced learning options in breadth and/or depth are offered for self-motivated students

\section{Basic components of specifications grading}

In specifications grading, learning outcomes are explicitly linked to the grading system. Thus, when a student earns an A, it is linked to a specific set of learning outcomes. The same is true for grades of B, C, and so on. Instructors identify the learning outcomes that must be met for each grade. The basic components of the approach include pass/fail grading (per letter grade) with no partial credit, modules of assessments that are tied to the learning outcomes of the course, a sequence of bundles that require more skill or content mastery to earn a higher grade, clear specifications and rubrics, and limited opportunities to revise unacceptable work. A 
foundational principle is that students complete the work to achieve the grade they choose, giving them ownership over their grades. A student may choose to adjust self-expectations, and therefore shift to a different bundle during the course $(A \rightarrow B$ or $C \rightarrow B)$ if the structure of the course supports this option. Selection of a grade bundle is not a guarantee of achievement (e.g., in order to receive an A, students must demonstrate the competencies required for the A). If the student does not demonstrate competency on assessments in a bundle, the student may attempt the next lower bundle $(\mathrm{A} \rightarrow \mathrm{B}, \mathrm{B} \rightarrow \mathrm{C})$.

\section{Linking grades to outcomes: creating grade bundles}

A learning outcome is an observable skill or behavior reflecting what a student should be able to do at the end of a course. In the specs grading approach, course structure is focused on the learning outcomes. Grades are linked to demonstrated learning outcomes that reflect achievement at a satisfactory level. Assessments are associated with each learning outcome. In other words, course grades correspond to meeting learning outcomes which directly correspond to assessments. Table 1 provides a sample mapping of certification standards for both SLP and AuD professions to learning outcomes and associated activities in an undergraduate course..$^{8,9}$

Table 1 here

In linking grades to outcomes, the instructor creates groups of assessments associated with one or more learning outcomes. Students receive grades based on the number of assessments or based on the nature of the specific assessments completed at a satisfactory level. To earn a higher grade, a student completes more assessments (breadth), assessments with advanced learning outcomes (depth), or both (breadth and depth). Bundles provide a structure, grouping assessments that correspond to a final grade that signifies attainment of the course's learning outcomes. The bundles associated with higher grades document more breadth and/or 
depth in demonstrating achievement of stated learning outcomes. Table 2 illustrates bundles for the undergraduate course referenced in Table 1.

Table 2 here

\section{Specifications}

The specifications (specs) are one or more requirements of an assessment, set by the instructor. The student's performance on the assessment must demonstrate satisfactory achievement of these specs to demonstrate competency with the linked learning objective. Instructors provide information, directions, rubrics, models, and so on, that clearly explicate the required specs. The instructor must know exactly what is required for satisfactory performance on the assessment and articulate this clearly. Students must understand the specs of each assessment to know exactly what needs to be done to demonstrate satisfactory or competent performance on an assessment. This is both demanding and liberating for instructors and students. Clarity of expectations is associated with great success at meeting them (see Table 3a and $3 b) .^{10,11}$

Table $3 a$ and $3 b$ here

\section{Pass-fail grading}

In professional fields, students demonstrate competency on the required knowledge and

Commented [WSA3]: I think these new tables are great! I reformatted Table $3 \mathrm{a}$ and will attach it, for your consideration. I think it's more readable to have a top vs. bottom orientation, instead of a left vs. right. See what you think.

Commented [LEEG4R4]: I think the orientation works well. Thanks for the compliment too!

Commented [PL<SoHS5R4]: Yes many thanks (-) skill outcomes in order to pass a course. The same principle applies in the specs approach; assessments are evaluated as pass or fail with no partial credit. Points based on a rubric may be used, but a threshold value is set to pass the assessment, and more points do not equate to a higher grade. If the student demonstrates satisfactory performance for the learning outcome, then the student receives a pass. If the student does not demonstrate the learning outcome (incomplete or unsatisfactory), then the student receives a fail. The instructor provides meaningful feedback 
on the assessment within a reasonable timeframe, and the student has some (limited)

opportunities to revise and resubmit assessments to demonstrate the learning outcome (see “Tokens" section below).

\section{Tokens}

The final component of the specs approach is creating a learning environment that minimizes risk with activities designed to foster creativity, broader learning, and student responsibility. The instructor needs to pass some control over learning to the student and respect how the student approaches the learning experience. To achieve this, the instructor creates and governs a token economy. Students are given a limited number of tokens at the outset of a course which can be used for a variety of instructor defined reasons. For example, tokens might be used for revising an unsatisfactory assessment, missing a class, leaving a class early, or submitting an assessment late without penalty. In addition, students may be allowed to earn tokens as part of the course, for instructor defined reasons, such as submitting work early, completing additional assessments, or attending related campus or community events.

The nature, quantity, and requirements associated with tokens is entirely at the instructor's discretion When implementing tokens, the amount provided at the start of a course can be difficult to initially determine. Starting with a lower number of tokens may be preferable to avoid the situation where more remediations of failed assessments can be attempted than desired by the instructor. Adjustments to the number of tokens may be made throughout the course as needed. A second consideration is to determine how tokens may be used and create guidelines for use. For example, a student may have five tokens at the start of the course where two may be used for a class absence or late attendance and three for a due date extension or remediation of a failed assessment.

Commented [PW6]: An example from your use of specs grading would be great here. I am happy to include some of mine if you want. I know exactly what you mean here because I've used the systems several times. But, I remember that this was somewhat confusing to me when I first learned about it. The same was true with "bundles" but I think your table exemplifies this well.

Commented [LEEG7R7]: Does this help?

Commented [PRW8R7]: Yes, it does! 


\section{Implementation}

For any well-designed course, it is important to know what we want students to demonstrate on completion of the course. Specs, as an approach, is no different: the instructor begins with an outcomes-focused course design. In developing the outcomes, the instructor asks, "What do I need my students to walk out of my class knowing, doing, and thinking?" and "What do they need for the next class or to start a professional job?" In the disciplines of audiology and speech-language pathology, we are perfectly situated to know what our outcomes are because they should align to certification standards. Academic course instructors identify the knowledge and skills needed for professional practice in their content area and link course learning outcomes directly to certification standards. Course design naturally incorporates infusing theory and evidence-based practice within the course, because the course is intrinsically linked to the certification standards.

Similarly. clinical education instructors focus on the application and development of knowledge coupled with the acquisition and refinement of clinical skills as outlined in certification standards. The explicit focus on knowledge application and skill acquisition in clinical education also lends itself to a specs approach. Students must demonstrate basic competency in knowing, thinking, and doing across the range of required clinical skills. For example, in speech-language pathology, students must demonstrate the ability to perform an oral-facial examination and in audiology students must be able to perform an auditory brainstem response test. For both examples, students must at a minimum competently demonstrate the skill (doing). For a student at the start of a program, the expectation or specification may be set at a basic "doing" level — perform an oral-facial examination or auditory brainstem response testfor a pass (i.e., B grade). Some students may demonstrate advanced knowledge or thinking skills
Commented [PW9]: Can you add a few paragraphs in this section that specifically discuss how clinical educators (supervisors) can use this approach when supervising student clinicians? This is the main audience for this issue. What are your experiences in the clinical setting versus academic?

Commented [LEEG10R10]: Theoretically it shouldn't differ from academics. See if this is clear.

Commented [PRW11R10]: I like it! 
such as clearly summarizing the results of an oral-facial examination (knowing) or interpreting the results of an auditory brainstem response test (thinking). Those students earn a higher pass (i.e., A) as supported by evidence of a higher level of critical or clinical thinking.

Over the course of a program, students refine basic clinical skills and the minimum competency focus changes to include different and more advanced clinical skills. For example, the basic competency required to pass may advance from performance of an oral-facial examination or auditory brainstem response test to more advanced skills such as detecting abnormalities and clearly summarizing the results of an oral-facial examination, or interpreting the results of an auditory brainstem response and creating a predicted audiogram. Again, some students may demonstrate advanced critical and clinical skills, and those students earn a higher pass.

In clinical education, it is essential to identify the core clinical skills aligned with certification standards in each clinical experience; a specs approach can help to set a pass and fail paradigm through the creation of a hierarchy of basic and advanced clinical skills across a term or program. Clinical education instructors can scaffold students from basic to advanced knowing, thinking, and doing across clinical skills through clear specifications coordinated with certification standards to prepare student for entry into the profession.

Commented [WSA12]: This is great - thanks for adding
it!

\section{Developing outcomes}

A reasonable way to begin developing outcomes is to create a map of the course through author $<3$ identification of foundational learning outcomes. The basic knowledge and skills that a student must achieve are outlined in our certification requirements, and in the specs approach, these become the floor (i.e., the minimal level of competency). The student must demonstrate competency in these identified knowledge and skill areas to pass the course (e.g., corresponding 
to a passing grade of $\mathrm{B}$ or $\mathrm{C})$. Table 4 shows an example from a graduate level course, identifying the certification standards associated with the course learning objectives.

Table 4 here

\section{Designing grade bundles}

In a pass/fail structure, the instructor designs the course with a dichotomous (pass/fail) mapping to standards. However, to create performance expectations above floor-level, the instructor would need to identify how students could demonstrate advanced competency in each course objective. Higher levels of learning would, thus, earn higher grades above and beyond the floor-level. For example, a higher grade is earned through demonstration of competency in a greater number of outcomes, demonstrated competency with more course material, or use of higher-level cognitive skills in meeting course objectives. Higher grades above the expected floor allow for invested students to attain matching rewards. Table 5 shows the development of achievement from pass-level performance to the highest level. In this example, higher grades represent a combination of increased breadth and depth, but it could be one or the other, depending on the instructor's aims.

Table 5 here

\section{Setting specifications}

For each assessment, detailed instructions must be created. As noted above, the specifications need to provide enough information that the student knows and can meet the performance expectations. Information may include directions, examples of completed work, and rubrics. All specifications need to be planned at the outset of the course. 


\section{Accomplishing pass-fail grading}

To determine the pass criteria for each assessment activity, it is necessary to identify the assessment's mapped learning outcome(s) and the level that would indicate basic competency. In some cases, assessment may not have a rubric. Instead, specific requirements must be met, such as class attendance, skill demonstration, or quiz completion. If pass-fail grading is used, the instructor should explain how the points that are earned for these activities contribute to the bundle. For example, assessments with a rubric using points must direct students to a threshold representing passing performance. Points are then used to guide the student to where effort should be prioritized in order to pass. Although an assessment may have many components and a complex rubric, an important challenge for the instructor is to determine which components of many are truly essential and design criteria that represent passing performance. Table 6a shows the points assigned for a clinical skill demonstration related to client counseling, with multiple components, structured to be a pass/fail assessment. Table $6 \mathrm{~b}$ shows weighting applied to the student's written documentation of the counseling session with a client. The cut off for both assessments is $80 \%$ of the total points. Note that it is possible to fail if one misses only a small number of important features. If an assessment does not meet the criteria or performance expectation, the student can choose to use a token to revise and resubmit (if the course is set up for this).

Table 6 a here

Table $6 \mathrm{~b}$ here

\section{Use of tokens}

Course design needs to provide flexibility. Each student should start the course with a designated number of virtual tokens. Tokens can be used at any point in the semester in a manner 
directed by the instructor. Determining the number of tokens to provide at the start of a course can be a challenge on the first use of a specs approach. For example, giving too many tokens gives student too much latitude in number of revisions, attendance, etc. The authors' experience has shown that it is helpful to offer 1) specific tokens relating to missing a class, and 2) separate tokens for revision/resubmission of assessments. In addition, there may be other stipulations about important activities for which a student cannot use a token.

\section{Introducing students to specifications grading}

Introducing students to this approach is a radical change if they have not experienced specs before. Initially, students may have difficulty grasping the idea that they should choose the grade that they will seek for a particular course and then work to achieve that grade. A specs grading approach is a change - like the use of seatbelts. Instructors need to introduce it in the syllabus and discuss it in the first class. In oral and written explanations of the approach, emphasis can be placed on student empowerment. That is, students select the bundle of assessments to complete for a desired grade, and students are responsible for meeting the performance expectations associated with the assessments in a chosen bundle. Higher grades require increased responsibilities and time directed towards achieving that bundle. Because decisions in working toward a particular grade are made by the student, use of the specs approach provides acknowledgement that students are balancing many responsibilities.

\section{Conclusions}

A specs approach is well suited to any course in speech-language pathology or audiology, including clinical practicum. Certification standards delineate the knowledge and skill required for professional entry, so it is logical that a course in our field, whether focused on knowledge or skill, could employ a specs approach. In specs, a letter grade is linked to outcomes, rather than 
points. Course learning outcomes are explicitly linked to certification standards, to assessments, and to the grading system. Instructors identify criteria for meeting learning outcomes in order to achieve each letter grade, and they provide clear expectations (i.e., specifications). In using this approach, instructors simplify grading. They facilitate student learning by providing feedback, offering students limited opportunities for revision. Students demonstrate competency, while being given the option for advanced learning in breadth and/or depth. Students are empowered and develop personal responsibility for learning, which prepares students to enter the workplace. Thus, the specifications grading approach has clear advantages for students, faculty, and programs. Change can be challenging, but the advantages of specs not only help students and instructors focus on the importance of academic and clinical competence, but also helps students develop skills to become lifelong learners as professionals.

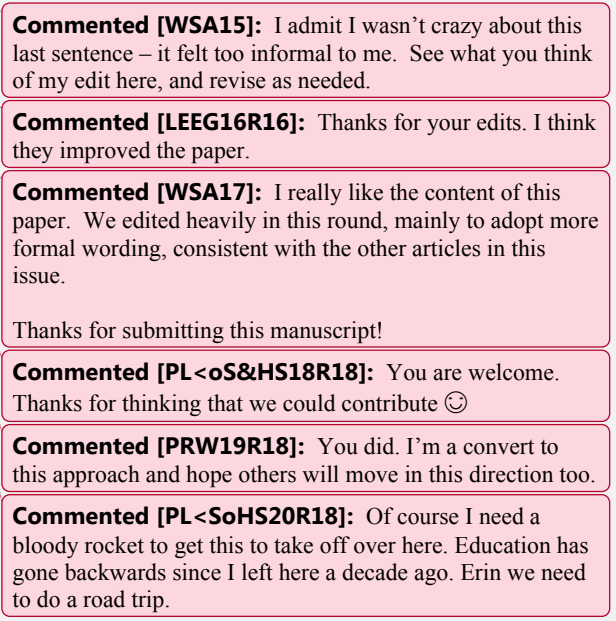




\section{References}

1. Lurie SJ. History and practice of competency-based assessment. Med Educ. 2012;46(1):49-57.

2. Nilson LB, Stanny CJ. Specifications grading : restoring rigor, motivating students, and saving faculty time. Sterling, Virginia: Stylus Publishing; 2015.

3. Yadav P, Chauhan VS, Bhat PS, Agarwal N, Yadav C, Bhatia S. Cross-sectional study of anxiety symptoms in students in preexamination period. Ind Psychiatry J. 2017;26(1):5663.

4. $\quad$ Rogers EM. Diffusion of innovations. 5th ed. ed. New York, N.Y.: Simon \& Schuster; 2003.

5. Nilson L. New ways to grade more effectively (essay). Inside HigherEd. https://www.insidehighered.com/views/2016/01/19/new-ways-grade-more-effectivelyessay. Published 2016. Accessed March 1, 2020.

6. Barr RB, Tagg J. From teaching to learning - a new paradigm for undergraduate education. Change. 1995;27(6):12-25.

7. Fixsen D, Naoom S, Blase K, Friedman R, Wallace F. Implementation research: A synthesis of the literature. University of South Florida, Louis de la Parte Florida Mental Health Institute, The National Implementation Research Network.

https://fpg.unc.edu/sites/fpg.unc.edu/files/resources/reports-and-policy-briefs/NIRNMonographFull-01-2005.pdf. Published 2005. Accessed 5 April, 2020.

8. Council for Clinical Certification in Audiology and Speech-Language Pathology of the American Speech-Language-Hearing Association. Standards and Implementation Procedures for the Certificate of Clinical Competence in Audiology. American SpeechLanguage-Hearing Association. https://www.asha.org/Certification/2012-AudiologyCertification-Standards/. Published 2012. Accessed 2020, March 6.

9. Council for Clinical Certification in Audiology and Speech-Language Pathology of the American Speech-Language-Hearing Association. 2014 (revised 2016) Standards and Implementation Procedures for the Certificate of Clinical Competence in SpeechLanguage Pathology. American Speech-Language-Hearing Association. https://www.asha.org/Certification/2014-Speech-Language-Pathology-CertificationStandards/. Published 2013. Accessed 2020, March 6.

10. Schwartz A, McDonald W, Vahabzadeh A, Cotes R. Keeping up with changing times in education: fostering lifelong learning of millennial learners. Focus (Am Psychiatr Publ). 2018;16(1):74-79.

11. Brown J, Marshall M. Great expectations: Optimism and pessimism in achievement settings. In: Chang E, ed. Optimism and pessimism: Implications for theory, research, and practice. Washington: American Psychological Association.; 2001:239-255. 
Specifications Grading

21

\section{Legend}

Table 1 Course objectives mapped to ASHA Standards for an undergraduate course

Table 2 Assessment bundles for an undergraduate course

Table 3a Comparison of instructions

Table $3 b$ Example of an associated rubric provided with the Specifications instructions

Table 4 Course objectives mapped to ASHA Standards for a graduate course

Table 5 Course bundles for graduate level course

Table 6a A complex activity pertaining to counseling a client as a pass/fail assessment

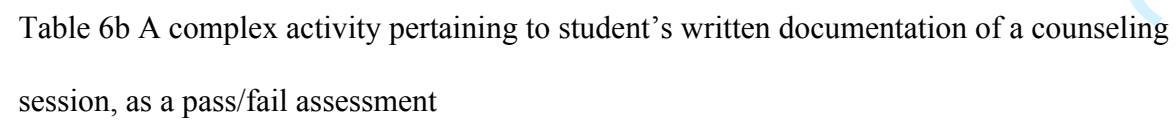

Table $6 \mathrm{~b}$ A complex activity pertaining to student's written documentation of a counseling session, as a pass/fail assessment

Commented [LEEG21]: Paula can you reorder and rename our documents?

Commented [PL <OS\&HS22R22]: Done. 
Table 1 Course objectives mapped to ASHA Standards for an undergraduate course

\begin{tabular}{|c|c|c|c|}
\hline Course Learning Objectives & Assessment & $\begin{array}{l}\text { SLP } \\
\text { Standards }\end{array}$ & $\begin{array}{l}\text { AUD } \\
\text { Standards }\end{array}$ \\
\hline $\begin{array}{l}\text { 1. Explain how the principles and rules of the ASHA Code } \\
\text { of Ethics relate to clinical management. }\end{array}$ & $\begin{array}{ll}\text { - } & \text { Quiz } \\
\text { - } & \text { Class Activity }\end{array}$ & $\begin{array}{l}\mathrm{IV}-\mathrm{E} \\
\mathrm{V}-\mathrm{B} 3 \mathrm{~d}\end{array}$ & IV-A 19 \\
\hline $\begin{array}{l}\text { 2. Describe how the scope of practice in speech-language } \\
\text { pathology and audiology relates to clinical } \\
\text { management. }\end{array}$ & $\begin{array}{ll}- & \text { Quiz } \\
- & \text { Class Activity }\end{array}$ & $\begin{array}{l}\text { IV-H } \\
\text { V-G }\end{array}$ & IV-A \\
\hline $\begin{array}{l}\text { 3. Explain how cultural and linguistic diversity influences } \\
\text { clinical management. }\end{array}$ & $\begin{array}{l}\text { - } \\
\text { - }\end{array}$ & $\begin{array}{l}\text { IV-D } \\
\text { V-B } 3 \\
\text { IV-G }\end{array}$ & IV-A 9, 16 \\
\hline $\begin{array}{l}\text { 4. Select effective techniques to gather information from } \\
\text { clients, families, and professionals. }\end{array}$ & $\begin{array}{ll}\text { - } & \text { Quiz } \\
\text { - } & \text { Class Activity } \\
\text { - } & \text { Simulation } \\
\text { - } & \text { Reflective Journal }\end{array}$ & $\begin{array}{l}\text { IV-D } \\
\text { V-B } 1 b\end{array}$ & IV-A 26 \\
\hline $\begin{array}{l}\text { 5. Identify how to gather observational information } \\
\text { including communication samples across the lifespan. }\end{array}$ & $\begin{array}{ll} & \text { Quiz } \\
- & \text { Class Activity } \\
\text { - } & \text { Simulation }\end{array}$ & $\begin{array}{l}\text { IV-D } \\
\text { V-B 1c }\end{array}$ & IV-C \\
\hline $\begin{array}{l}\text { 6. Describe and evaluate critical factors related to test } \\
\text { construction (e.g. validity, reliability) and test } \\
\text { administration. }\end{array}$ & $\begin{array}{l}\text { - } \text { Quiz } \\
\text { - Class Activity } \\
\text { - Simulation } \\
\text { - Test Assignment }\end{array}$ & $\begin{array}{l}\text { IV-D } \\
\text { V-B 1C }\end{array}$ & IV-A 11 \\
\hline $\begin{array}{l}\text { 7. Create functional treatment objectives including } \\
\text { measurement of outcome data. }\end{array}$ & $\begin{array}{l}\text { - Class Activity } \\
\text { - } \quad \text { Simulation }\end{array}$ & $\begin{array}{l}\text { IV-D } \\
\text { V-B 2a }\end{array}$ & IV-D \\
\hline
\end{tabular}


Specifications grading

Table 2 Assessment bundles for an undergraduate course

\begin{tabular}{|l|c|c|c|c|}
\hline Task and Date & Bundle D & Bundle C & Bundle B & Bundle A \\
\hline 23 or more class activities & $\checkmark$ & $\checkmark$ & $\checkmark$ & $\checkmark$ \\
\hline 90\% quiz average on 10 quizzes & & $\checkmark$ & $\checkmark$ & $\checkmark$ \\
\hline Simulation Test Administration \& Scoring & & $\checkmark$ & $\checkmark$ & $\checkmark$ \\
\hline Simulation Assessment & & & $\checkmark$ & $\checkmark$ \\
\hline Simulation Intervention & & & $\checkmark$ & $\checkmark$ \\
\hline Test Review & & & & $\checkmark$ \\
\hline Simulation Assessment \# 2 & & & & $\checkmark$ \\
\hline 4 reflective learning journals for Simulation Assessment \#2 & & & & $\checkmark$ \\
\hline
\end{tabular}


2

3

4

5

6

7

8

9

Table 3a Comparison of instructions

\begin{tabular}{|c|}
\hline Non-Specifications Example Instructions \\
\hline Presentations include the following: \\
10-minute summary of (a) one clinical \\
case (the student has worked with this \\
term) and (b) current research article \\
related to the selected clinical case \\
5-minute period of questions posed by \\
audience members \\
$\circ \quad$ Classmates will be allowed up to 4 \\
minutes of questions; faculty/SLPs \\
allowed the remainder of time.
\end{tabular}

Specifications Example Instructions

Presentations include the following:

The summary section should address the following:

- A brief descriptive summary of one clinical case from this term.

- A brief summary of information from one recent research (data-based) article that is relevant to the case including:

- Article citation

- Brief statement of search strategy terms used, and databases checked.

- Clear rationale for selecting the article

- Explain how the article relates to your clinical case.

- Summarize key information from the research article (i.e., participants, methods, results, etc.)

- Critical appraisal of the study

- Consider factors such as design, participants, methods, results, validity, level of evidence, etc.

- Explicitly discuss application of the content to your case.

- Did the article change your understanding of your case $\& /$ or how would you use the information with future clinical cases?

- Students may use up to 3 PowerPoint slides. No handouts.

- Students must keep within the defined time frames allotted (i.e., 10-minute summary).

- The presentation should be verbally presented and NOT read to the audience. Students may bring notes, notecards, or an outline to follow. 
Table $3 b$ Example of an associated rubric provided with the Specifications Instructions

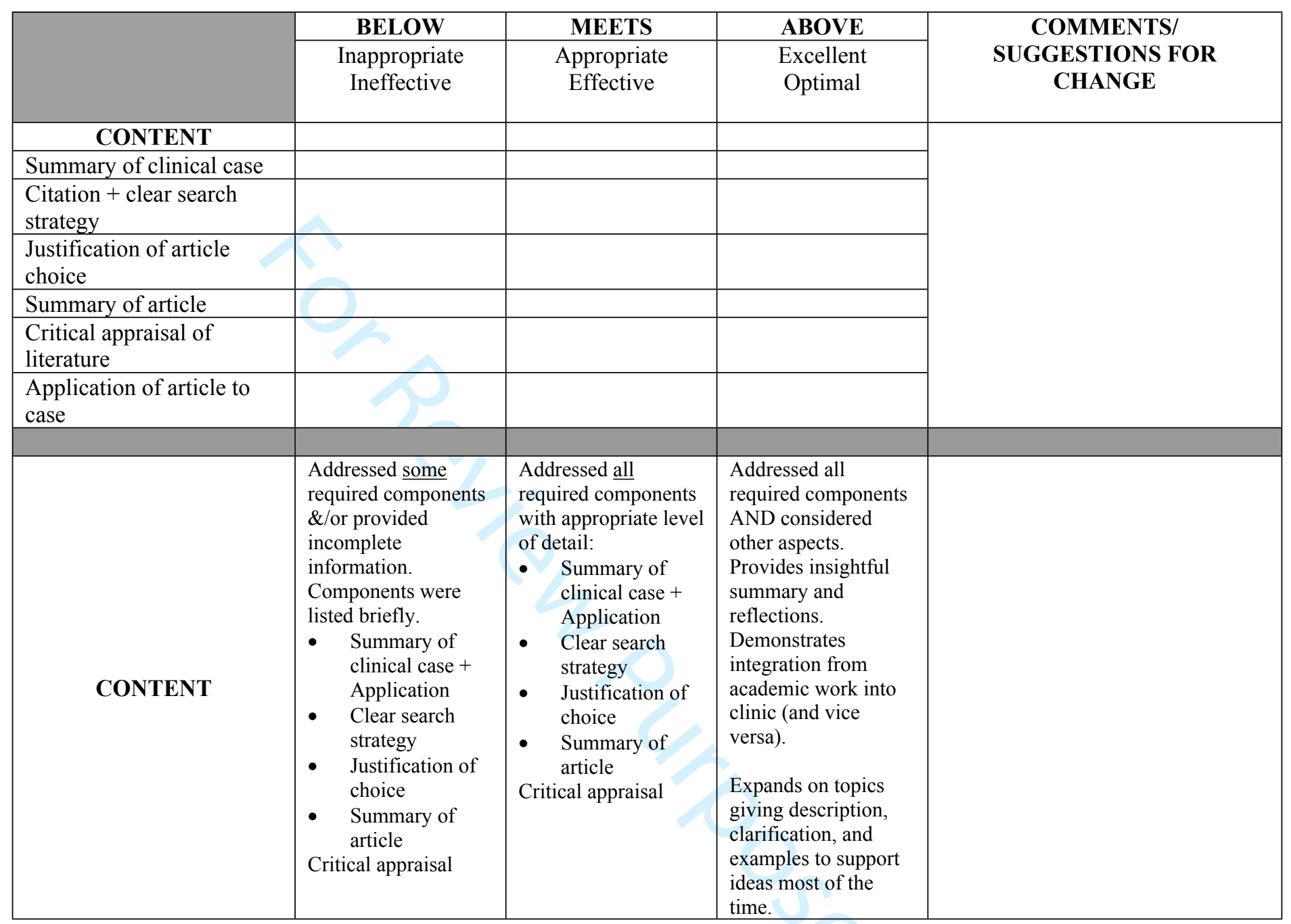


Table 4 Course objectives mapped to ASHA Standards for a graduate course

\begin{tabular}{|c|c|c|}
\hline ASHA Standards & Course Learning Objectives & Learning Activity/Evidence \\
\hline $\begin{array}{l}\text { Standard IV-B } \\
\text { The student will demonstrate } \\
\text { knowledge of basic human } \\
\text { communication and swallowing } \\
\text { processes, including the } \\
\text { appropriate biological, neurological, } \\
\text { acoustic, psychological, } \\
\text { developmental, and linguistic and } \\
\text { cultural bases. The student will } \\
\text { demonstrate the ability to integrate } \\
\text { information pertaining to normal } \\
\text { and abnormal human development } \\
\text { across the life span. }\end{array}$ & $\begin{array}{l}1.1 \text { Explain the relation between oral and } \\
\text { written language and the development of } \\
\text { written language. }\end{array}$ & $\begin{array}{l}\text { Quizzes } \\
\text { Portfolio of Application } \\
\text { Activities }\end{array}$ \\
\hline $\begin{array}{l}\text { Standard IV-C } \\
\text { The student will demonstrate } \\
\text { knowledge of communication and } \\
\text { swallowing disorders and } \\
\text { differences, including the } \\
\text { appropriate etiologies, } \\
\text { characteristics, } \\
\text { anatomical/physiological, acoustic, } \\
\text { psychological, developmental, and } \\
\text { linguistic and cultural correlates in } \\
\text { the following areas: } \\
\text { - Receptive/expressive } \\
\text { language } \\
\text { - Hearing } \\
\text { - Cognitive aspects of } \\
\text { communication } \\
\text { Social aspects of } \\
\text { communication }\end{array}$ & $\begin{array}{l}\text { 2.1 Define language and literacy disorders in } \\
\text { school-age children. } \\
\text { 2.2 Summarize methods that reduce cultural } \\
\text { or linguistic bias in assessment and treatment } \\
\text { procedures. } \\
2.3 \text { Organize and present information about } \\
\text { the management of pediatric language } \\
\text { disorders associated with various } \\
\text { exceptionalities. }\end{array}$ & $\begin{array}{l}\text { Quizzes } \\
\text { Portfolio of Application } \\
\text { Activities }\end{array}$ \\
\hline
\end{tabular}


Table 5 Course bundles for graduate level course

Bundle C

Complete ALL quizzes with an $80 \%$ average or higher

Bundle B (Includes all the requirements for Bundle C)

Complete ALL quizzes with an $80 \%$ average or higher

Compile portfolio of activities ( $80 \%$ criteria or higher on ALL portfolio items)

Simulations ( $80 \%$ performance or higher on ALL assigned cases)

Bundle A (Includes all the requirements for Bundle C and B.)

Complete ALL quizzes with an $80 \%$ average or higher

Compile portfolio of activities ( $80 \%$ criteria or higher on ALL portfolio items)

Simulations ( $80 \%$ performance or higher on ALL assigned cases)

Complete 3 article appraisals

Create a special populations handout 


\begin{tabular}{|l|l|l|}
\hline Oral Practical Criteria & Possible Points & Points \\
\hline Rapport & & \\
\hline Clear introduction to client & 1 & \\
\hline Maintained appropriate eye contact & 1 & \\
\hline Appropriate posture/body language & 1 & \\
\hline Avoided jargon & 1 & \\
\hline Information & & \\
\hline Actively listened to client & 1 & \\
\hline Got required information & 1 & \\
\hline Used at least 3 different response types & 1 & \\
\hline $\begin{array}{l}\text { Used at least 1 type of strategy to help client identify or evaluate a goal } \\
\text { for use in treatment }\end{array}$ & 1 & \\
\hline "Hook" action established* & 1 & \\
\hline Questions & 1 & \\
\hline Let person finish before answering & & \\
\hline Clarity and relevance of answers & 1 & \\
\hline Closing & 1 & \\
\hline Stopping the session! & & \\
\hline Recap client's problem & 1 & \\
\hline Acknowledge plan & 1 & 1 \\
\hline “Hook" action* & 1 & \\
\hline
\end{tabular}

\section{*The "hook" action is a specific mini-objective that the client identifies that is a first step to} tackling their goal., e.g. For example, if the client was the parent of a young child, the hook action might be to calling the school to find out when the teacher is available for discussion, leading up to the goal of having the discussion with the teacher about child's classroom behavior, or if the client was a teacher with a voice problem, the hook might be to do some internet $\underline{\text { searching about different types of voice amplification system, before committing to the goal of }}$ $\underline{\text { using a system in class- }}$

Commented [WSA1]: Can you clarify "hook"? Commented [PL<OS\&HS2R2]: OK?

Commented [PRW3R2]: Is this "hook" for the parent? I think it needs another sentence setting context. I think I understand what "hook" is but I'm not sure.

Commented [WSA4]: Should this last line be "Hook action discussed with client" or "Client commits to "hook" action"? There needs to be some more context here.

Commented [WSA5]: Your definition involves a client, but your example involves the parent of the client. Could you instead use as an example, "For example, client contacts the teacher to find out when she may be available for additional help." 
Table $6 \mathrm{~b}$ A complex activity pertaining to student's written documentation of a counseling session, as a pass/fail assessment

\begin{tabular}{|l|l|l|}
\hline Written Criteria & Possible Points & Points \\
\hline Information & & \\
\hline Summary of client details & 1 & \\
\hline Summary of client concerns & 2 & \\
\hline $\begin{array}{l}\text { Emotional reactions clients may exhibit as a result of their } \\
\text { communication difficulties }\end{array}$ & 2 & \\
\hline Cultural considerations & & \\
\hline Strategies & 3 & \\
\hline Scope of practice & 4 & \\
\hline Relevant issue identified & & \\
\hline Appropriate professional identified for onward referral & 2 & \\
\hline Appropriate referral procedure identified & 1 & \\
\hline Writing & 1 & \\
\hline Clear & & \\
\hline Avoids jargon & 1 & 1 \\
\hline
\end{tabular}

